\title{
Identification of the maize Mediator CDK8 module, and Dissociation insertional mutagenesis of $\mathrm{ZmMed12a}$
}

\author{
Tania Núñez-Ríos ${ }^{1 \dagger}$, Kevin R. Ahern ${ }^{2}$, Ana Laura Alonso-Nieves ${ }^{1}$, Daniel Lepe-Soltero ${ }^{1}$, \\ Carol Martínez-Camacho ${ }^{1 \dagger}$, Marcelina García-Aguilar ${ }^{1}$, Thomas P. Brutnell $^{3}, \mathbf{C}$. \\ Stewart Gillmor* ${ }^{1}$ and Ruairidh James Hay Sawers* ${ }^{1}$ \\ ${ }^{1}$ Laboratorio Nacional de Genómica para la Biodiversidad (LANGEBIO), Unidad de \\ Genómica Avanzada, Centro de Investigaciones y de Estudios Avanzados del Instituto \\ Politécnico Nacional (CINVESTAV-IPN), Irapuato, Guanajuato, México. \\ ${ }^{2}$ Boyce Thompson Institute for Plant Research, Ithaca, New York, U.S.A. \\ ${ }^{3}$ Donald Danforth Plant Science Center, St. Louis, Missouri, U.S.A. \\ ${ }^{\dagger}$ Current address: PLANAMERICA, Michoacán, México (TN-R); Universidad Intercultural \\ de Chiapas, México (CM-C) \\ *Correspondence: \\ Stewart Gillmor \& Ruairidh Sawers \\ Laboratorio Nacional de Genómica para la Biodiversidad (LANGEBIO), Unidad de \\ Genómica Avanzada, Centro de Investigaciones y de Estudios Avanzados del Instituto \\ Politécnico Nacional (CINVESTAV-IPN), Irapuato, Guanajuato, México. \\ stewart.gillmor@cinvestav.mx; rusawers@cinvestav.mx
}

\section{ABSTRACT}

Mediator is a conserved transcriptional co-activator that links transcription factors bound at enhancer elements to RNA Polymerase II. Mediator-RNA Polymerase II interactions can be sterically hindered by the Cyclin Dependent Kinase 8 (CDK8) module, a submodule of Mediator that acts to repress transcription in response to discrete cellular and environmental cues. The CDK8 module is conserved in all eukaryotes and consists of 4 proteins: CDK8, CYCLIN C (CYCC), MED12, and MED13. In this study, we have characterized the CDK8 module of Mediator in maize. The maize genome contains single copy genes for $C d k 8, C y c C$, and Med13, and two genes for Med12. Analysis of expression data for the CDK8 module demonstrated that all five genes are broadly expressed in maize tissues, with $\mathrm{ZmMed12a}$, $Z m M e d 12 b$, and ZmMed13 exhibiting similar expression patterns. We performed a Dissociation $(D s)$ insertional mutagenesis, recovering two independent insertions in the $\mathrm{ZmMed} 12 \mathrm{a}$ gene. One of these $\mathrm{Ds}$ insertions results in a truncation of the $\mathrm{ZmMed} 12 \mathrm{a}$ transcript. Our molecular characterization of the maize CDK8 module, as well as transposon tagging of ZmMed12a, establish the basis for molecular and functional studies of these important transcriptional regulators in Zea mays. 
KEYWORDS Zea mays, Dissociation, Mediator, CDK8 module, Med12, Med13, CycC

\section{INTRODUCTION}

43 Transcriptional regulation plays an essential role in almost all aspects of development and

44 physiology, including responses to the biotic and abiotic environment. One key regulator of transcription is Mediator, a multiprotein complex conserved from yeast to plants to animals, which was initially identified based on its requirement for transcription of virtually all protein-coding genes (Kelleher et al., 1990; Flanagan et al., 1991; Bourbon, 2008). The Core Mediator consists of Head, Middle and Tail domains, and typically functions as a transcriptional co-activator, linking transcription factors bound at upstream enhancer elements to RNA polymerase II (RNA pol II) (reviewed in Yin and Wang, 2014; Allen and Taatjes, 2015). The Head and Middle domains interact with RNA pol II, while the Tail domain is thought to interact with specific transcription factors (Tsai et al., 2014; Robinson et al., 2015; Plaschka et al., 2015; reviewed in Larivière et al., 2012). A fourth Mediator module shows transient association with Core Mediator and often acts to repress transcription. This Cyclin Dependent Kinase 8 (CDK8) module is composed of the proteins MED12, MED13, CYCLIN C (CYCC), and CDK8 (reviewed in Björklund and Gustafsson, 2005). In agreement with the variable association of the CDK8 module with Core Mediator, purification of Mediator from Arabidopsis thaliana yielded both conserved Core Mediator subunits, as well as subunits unique to Arabidopsis, but did not include components of the CDK8 module (Bäckström et al., 2007).

In yeast and animals, components of the CDK8 module can regulate transcription in several ways, with different subunits playing different roles. One mechanism for transcriptional repression involves steric inhibition, where the CDK8 module occupies the Core Mediator pocket that binds RNA pol II, thereby preventing interaction of Core Mediator and RNA pol II (Elmlund et al., 2006; Tsai et al., 2013). Transcriptional repression by this steric mechanism has the potential to be dynamic, as the occupancy of the RNA pol II binding pocket can be modulated during subsequent rounds of assembly of the MediatorRNA pol II holoenzyme (reviewed in Allen and Taatjes, 2015). This steric mechanism involves all four units of the CDK8 module, with the MED13 subunit playing the most important role, interacting directly with the Middle domain of Core Mediator (Knuesel et al., 2009; Tsai et al., 2013). The MED13 subunit also serves an important function in regulation of CDK8 module stability: phosphorylation of a conserved phosphodegron site in MED13 can lead to recognition by a ubiquitin ligase complex, and subsequent degradation (Davis et 74 al., 2013).

In Arabidopsis, components of the CDK8 module were initially identified by their requirement for development, and also affect the response to fungal pathogens and cellular stress. Mutations in $C D K 8$ were identified as enhancers of the phenotype of the floral homeotic mutant hualhua2, and thus were named hua enhancer 3 (hen3). hen3 mutants demonstrated to have CDK8 kinase activity (Wang and Chen, 2004). CDK8 regulates 
retrograde signaling from the mitochondria to the nucleus in response to $\mathrm{H}_{2} \mathrm{O}_{2}$ and cold stress (Ng et al., 2013). CDK8, as well as $M E D 12$ and $M E D 13$, are also required for the response to both fungal and bacterial pathogens (Zhu et al., 2014).

Mutations in MED12 and MED13 were initially reported from a genetic screen for regulators of pattern formation in Arabidopsis embryogenesis, and were named center city (cct) and grand central (gct), to reflect the increased size of the shoot apical meristem (SAM) in these mutants. $c c t$ and gct mutants delay the timing of pattern formation during embryogenesis, rather than affecting pattern formation per se- the increased size of the SAM in $c c t$ and gct mutants can be attributed to its formation later in embryogenesis compared to the wild type (wt) (Gillmor et al., 2010). The delayed formation of the SAM may be related to auxin signaling, as both the med13 allele macchi-bou2 (mab2), and the med12 allele cryptic precocious ( $\mathrm{crp}$ ) act as enhancers of a mutation in the auxin dependent kinase PINOID (Furutani et al., 2004; Ito et al., 2011; Imura et al., 2012). Importantly for mechanistic studies of CDK8 module function in Arabidopsis, Ito et al. (2011) demonstrated that the MED13 and CDK8 proteins are both able to interact with Cyclin C, as has previously been demonstrated in Drosophila (Loncle et al., 2007). Consistent with studies showing auxin-related phenotypes for mutants in MED12 and MED13, a recent study showed that both of these genes, as well as $C D K 8$, are involved in auxin transcriptional responses, and that the MED13 protein relays signals from the IAA14 protein to repress the auxin responsive transcription factors ARF7 and ARF19 (Ito et al., 2016).

In addition to affecting the timing of pattern formation in embryogenesis, MED12 and $M E D 13$ also regulate the timing of post-embryonic phase transitions in Arabidopsis. A dominant allele of med12 (named cryptic precocious (crp-1D)) was isolated in a genetic screen for enhancers of the early flowering phenotype conditioned by overexpression of the florigen FT (Imura et al., 2012). Loss of function mutants in $\mathrm{crp} / \mathrm{cct}$ and gct show late flowering due to overexpression of the floral repressor FLOWERING LOCUS C (FLC), as well as decreased expression of the floral promoters FLOWERING LOCUS (FT), TWIN SISTER OF FT (TSF), SUPPRESSOR OF OVEREXPRESSION OF CONSTANTS 1 (SOC1), APETALA 1 (AP1) and FRUITFULL (FUL) (Imura et al., 2012; Gillmor et al., 2014). cct and gct mutants also misexpress seed specific genes during seedling development, and have an elongated vegetative phase due to overexpression of the microRNA miR156 (Gillmor et al., 2014), a master regulator of the vegetative phase in plants (Wu et al., 2009). Taken together, these results demonstrate that MED12 and MED13 act as master regulators of developmental timing in plants, regulating the timing of pattern formation in embryogenesis, the seed-toseedling transition, vegetative phase change, and the transition to flowering (Gillmor et al., 2010; Ito et al., 2011; Imura et al., 2012; Gillmor et al., 2014).

Due to its importance in plant development and physiology, we have extended studies of the CDK8 module to the crop plant maize (Zea mays). Establishment of molecular and genetic resources for the study of the maize CDK8 module will allow evaluation of its role in the regulation of agricultural traits such as timing of flowering and seed development, as well as responses to biotic and abiotic stresses. One of the primary goals of this work was isolation of loss of function mutant alleles of maize CDK8 module-encoding genes. In maize, resources based on endogenous DNA transposons constitute the most accessible and widelyused technology for reverse genetics (McCarty and Meeley, 2009). The two major transposon 
125 systems used for gene tagging in maize are Activator/Dissociation (Ac/Ds) and Mutator $(\mathrm{Mu})$

126 (Candela and Hake, 2008). These systems consist of an autonomous or master element that encodes a transposase (TPase) and a second non-autonomous or receptor element. The receptor elements are frequently derived from a master element by mutations within the TPase gene. Lacking TPase, non-autonomous elements are stable, unless mobilized by TPase supplied in trans by an autonomous element (Kunze et al., 1997). Ac is a member of the hAT transposon superfamily (named after the founding members hobo, Ac and Tam3; Calvi et al., 1991) and moves via a cut-and-paste mechanism (Bai et al. 2007), with a preference for transposition to linked sites, making the system ideal for local mutagenesis (Greenblatt, 1984; Dooner and Belachew, 1989; Brutnell and Conrad, 2003). To exploit the $A c / D s$ system for reverse genetics, $D s$ elements have been distributed throughout the genome to provide potential "launch pads" for mutagenesis of nearby genes (Vollbrecht et al. 2010).

In this study, we identify five genes encoding components of the CDK8 module in maize, present experimentally determined gene structures, and report expression of corresponding transcripts. We performed $D s$ mutagenesis of the gene $Z m M e d 12 a$, identifying two novel insertional alleles, one of which results in a truncation of the ZmMed12a transcript. These insertional mutant alleles will enable determination of the biological roles of the CDK8

142 module in maize development and stress responses.

\section{MATERIALS AND METHODS}

\section{Identification of maize CDK8 module genes}

146 Maize CDK8 module genes were identified by BLAST searches using the predicted Arabidopsis thaliana protein sequences for HEN3/CDK8 (AT5G63610), CYCC1;1 (At5g48640), CCT/MED12 (At4g00450), and GCT/MED13 (At1g55325) available at TAIR (www.arabidopsis.org). Reciprocal BLAST searches were conducted between all maize and Arabidopsis sequences, to establish that the five maize genes $\mathrm{ZmCDK8}, \mathrm{ZmCycC}, \mathrm{ZmMed} 12 a$, $\mathrm{ZmMed} 12 \mathrm{~b}$, and $\mathrm{ZmMed} 13$ were the only full length CDK8 homologs present in maize.

154 Multiple mRNA sequences with full-length coding sequences (as well as upstream and

Determination of coding sequences for $\mathrm{ZmCDK8}, \mathrm{ZmCycC}, \mathrm{ZmMed12a}, \mathrm{ZmMed12b}$, and ZmMed13 downstream untranslated regions) were identified from the NCBI database for both $\mathrm{ZmCDK} 8$ and $\mathrm{ZmCycC}$. For $C D K 8$, cDNAs for two alternative splice products were identified: EU968864, NM_001157457 and BT018448 correspond to one splice variant, and BT039744 and XR_552425 correspond to the other splice variant. For $C y_{c} C$, three independent cDNAs (BT040922, BT033427, and XM008652706) were identified for the one splice variant (shown in Figure 1). Two independent cDNAs (AY105730 and EU972675) represented another $C y c C$ splice variant with an identical coding sequence but with slight differences in the 3'UTR. A third splice variant was represented by a single cDNA (BT036293); this mRNA has two upstream ORFs, and encodes a truncated CycC protein. For ZmMed12a,

165 (maizegdb.org), which were then confirmed and extended by RT-PCR using RNA extracted 
166 from seedlings of the B73 inbred line. To confirm the ZmMed12a, ZmMed12b, and

$167 \mathrm{ZmMed} 13$ gene models, we amplified cDNA products covering the entire predicted coding 168 regions. Given their large expected size, ZmMed12a, ZmMed12b, and ZmMed13 cDNAs

169 were amplified in multiple over-lapping fragments. Sequencing of cDNA products was generally consistent with gene models based on genomic sequence analysis, except in the case of $\mathrm{ZmMed13}$, where a large intron not present in the maize genome sequence was discovered. Coding sequences were deposited in the NCBI database with the following accession numbers: ZmMed12a (KP455660), ZmMed12b (KP455661), and ZmMed13

175 In addition, numerous short genes that are predicted to encode highly truncated ZmMed12 proteins of 199 to 431 residues were identified (Núñez-Ríos, 2012). These short ZmMed12 genes are predicted to encode the Med12 domain (pfam09497) and many have corresponding expressed sequence tags (EST) (B73 RefGen_v3), which do not cover the entire body of these short genes. Analysis of genomic sequences around these predicted coding sequences did not identify additional Med12 exons (data not shown), suggesting that these are indeed truncated versions of $\mathrm{ZmMed12}$, and not mis-annotated genes with nearby exons that would constitute the middle and C-terminal portions of Med12 proteins.

\section{Expression profiles of maize CDK8 module genes}

Expression data from 22 maize tissues were obtained from http:/qteller.com/qteller3/ on August 2014, in the form of Fragments Per Kilobase of transcript per Million (FPKM). In order to look for correlations between pairs of genes across the tissues, the data was $\log 2$ transformed (first adding 1, to avoid the logarithm of 0 ) and normalized using the normalizeQuantiles function from the limma package (Bolstad et al., 2003).

The expression values were selected for the 5 CDK8 module genes: $C D K 8$ (GRMZM2G166771), CycC (GRMZM2G408242), Med12a (GRMZM2G114459), Med12b.1 (GRMZM5G828278), Med12b.2 (GRMZM5G844080), Med13.1 (GRMZM2G053588), and Med13.2 (GRMZM2G153792). Since Med12b.1 and Med12b.2 as well as Med13.1 and Med13.2 are spliced versions of the same gene, the geometric mean was calculated to obtain an averaged estimate of their expression. These data were employed to produce Figure 2A, using the heatmap.2 function from the gplots package (Warns et al., 2015). All pair-wise combinations of the 5 genes across all tissues were plotted using the generic plot function in R (R Core Team, 2015) (Figure S5). The Pearson correlations for all possible pairs of genes were calculated with the cor function, and these data were used as the empirical null to calculate p-values. Correlations for CDK8 module genes were calculated separately. The blob plot in Figure 2B was generated with the corrplot for R.

\section{Description of maize stocks}

All stocks were maintained in the common genetic background of a color-converted W22 inbred line (Dooner \& Kermicle, 1971). A stable source of $A c$ transposase was provided by Ac-immobilized (Ac-im), an Ac derivative which has lost $10 \mathrm{bp}$ at the 5' end of the element, preventing excision (Conrad and Brutnell, 2005). Activity of $A c$ transposase was monitored using the mutable $D s$ reporter $r 1-s c: m 3$ that carries a $D s 6$-like insertion in the $r 1$ locus that controls anthocyanin production in the aleurone and scutellum tissues (Alleman and 
211 Kermicle, 1993): when $A c$ transposase is present, excision of $D s$ from $r 1$ restores gene

212 function producing colored sectors (Brutnell \& Dellaporta, 1994). The donor $D s(d D s)$ stock

$213 d D s-B . S 07.0835$ was generated by isolation of novel transpositions from $r 1-s c: m 3$ as

214 previously described (Vollbrecht et al., 2010). Presence of $d D s-B . S 07.0835$ was assayed by PCR as previously described (Vollbrecht et al., 2010) using a combination of the $D s$ end primer JSR05 and a primer specific to the genomic site of B.S07.0835 (5'-

218 GACGCACACACGTCAGTATAG-3'). To generate the test-cross population, plants verified as carrying the donor $d D s-B . S 07.0835$ with $A c$-im in the genetic background were used as males to pollinate $r 1-s c: m 3 / r 1-s c: m 3$ female plants.

\section{Seedling screen for transposon insertions in $\mathrm{ZmMed12a}$}

221

Testcross progeny were germinated and screened for novel insertions of $D s$ in $Z m M e d 12 a$ using a PCR-based strategy. Tissue was collected between 7 and 10 days after planting from pools of 10 -18 seedlings using a $\approx 3 \mathrm{~mm}$ hole punch, and DNA was isolated following a CTAB-based extraction protocol (Weigel and Glazebrook, 2009). A total of $10 \mathrm{ZmMed} 12 \mathrm{a}$ gene-specific primers were designed, covering a region extending from $1.8 \mathrm{~kb}$ upstream of the translational start to the stop codon. These were used in conjunction with the 5' and 3' $\mathrm{Ds}$ end primers JSR01 and JGp3, respectively, to amplify DNA adjacent to novel $D s$ insertions in ZmMed12a (Table 1). Pools amplifying a product were de-convoluted by screening individuals separately; this second round of PCR used DNA extracted from a different seedling leaf than that sampled for the pool to reduce the chances of recovering somatic transposition events. The PCR products of the second PCR were cleaned (Sambrook and Russell, 2006) and the DNA concentration was adjusted for sequencing by the GENEWIZ insertional alleles were grown to maturity and propagated by both self-pollination and outcrossing to W22 and B73 inbred lines.

\section{RT-PCR analysis of zmmed12a-1::Ds and zmmed12a-2::Ds alleles}

237 DNA was extracted from 10 day old greenhouse grown seedlings of F2 populations segregating the $1: \because D s$ and $2: \because D s$ insertions. Seedlings were genotyped using primers to identify homozygous wild type and homozygous insertion alleles for $1: \because D s$ (primer pair A5.12F and A5.12R for wild type and A5.12F and JGp3 for Ds insertion) and $2: \because D s$ (primer pair $\mathrm{C} 2.7 \mathrm{~F}$ and $\mathrm{C} 2.7 \mathrm{R}$ for wild type allele and C2.7R and JGp3 for $D s$ insertion). RNA was then extracted Trizol (Invitrogen) for wild type and homozygous insertion alleles. Reverse transcription was performed with SuperScript II (Invitrogen). PCR was performed with the following programs, using Kapa Taq Polymerase (Kapa Biosystems). TNC4-TNC5 primer pair: initial denaturation $95^{\circ} \mathrm{C} 5^{\prime} ; 10$ cycles of $95^{\circ} \mathrm{C} 30^{\prime}, 60^{\circ} \mathrm{C} 30^{\prime \prime}\left(-0.5^{\circ} \mathrm{C}\right.$ per cycle $)$, $72^{\circ} \mathrm{C} 45^{\prime}$ '; 27 cycles of $95^{\circ} \mathrm{C} 30^{\prime}$ ', $55^{\circ} \mathrm{C} 30^{\prime},, 72^{\circ} \mathrm{C} 45^{\prime}$ '; final extension $72^{\circ} \mathrm{C} 5^{\prime}$. RS170RS167 and ZmCDK primer pairs: initial denaturation $95^{\circ} \mathrm{C} 5^{\prime} ; 30$ cycles of $95^{\circ} \mathrm{C} 30^{\prime}$, $60{ }^{\circ} \mathrm{C} 30 ',, 72^{\circ} \mathrm{C} 1$ '; $72{ }^{\circ} \mathrm{C} 10^{\prime}$. 


\begin{tabular}{|c|c|c|}
\hline Name & Sequence & Purpose \\
\hline B.S07.0835 & 5'-GACGCACACACGTCAGTATAG-3' & Donor Ds site \\
\hline JGp3 & 5'-ACCCGACCGGATCGTATCGG-3' & Ds specific \\
\hline JSR01 & 5'-GTTCGAAATCGATCGGGATA-3' & Ds specific \\
\hline JSR05 & 5'-CGTCCCGCAAGTTAAATATGA-3' & Ds specific \\
\hline 5'UTRF & 5'-TGCACTGCTGCTGTCCTATT-3' & ZmMed12a specific- Ds tagging \\
\hline E03R & 5'-TGGTCCATAACTCAGACATACTTGT-3' & ZmMed $12 a$ specific- Ds tagging \\
\hline E03F & 5'-CTCCCTAATACCCCTGTATTTCA-3' & ZmMed12a specific- Ds tagging \\
\hline E07R & 5'-GCATTTGGTAGTAAACAAGAGATGG-3' & ZmMed12a specific- Ds tagging \\
\hline E06F & 5'-CCTTGTTAGAATGCGGTCAA-3' & ZmMed12a specific- Ds tagging \\
\hline E09.2R & 5'-TCAGGACGAACATACCTAAGCA-3' & ZmMed $12 a$ specific- Ds tagging \\
\hline INT02F & 5'-ACCAAGTTTGTCAGGTCAACG-3' & ZmMed12a specific- Ds tagging \\
\hline E10.2R & 5'-CTACCGAAAACCCATGTTGG-3' & ZmMed $12 a$ specific- Ds tagging \\
\hline E10.2F & 5'-GCAGCTTTTGAGAGGTTTGAA-3' & ZmMed $12 a$ specific- Ds tagging \\
\hline E12R & 5'-GCAACTTCCGTCAGCCTTAG-3' & ZmMed $12 a$ specific- Ds tagging \\
\hline RS170 & CTGGCGAAAGCCTTTTTGAGAAGC & RT-PCR for Ds insertion \\
\hline RS167 & CCCCCACAGGCCCTAACTAAAACA & RT-PCR for Ds insertion \\
\hline TNC4 & CCATATGAGGAACTTCACTCCAG & RT-PCR for Ds insertion \\
\hline TNC5 & ACCTGTACAGAAGTCTGTTAAGCAA & RT-PCR for Ds insertion \\
\hline $\mathrm{ZmCDKF}$ & GGAAGGTATGCACAGGACAGAT & RT-PCR for Ds insertion \\
\hline $\mathrm{ZmCDKR}$ & TTCAGCACAATCTTGGCAAAAC & RT-PCR for Ds insertion \\
\hline
\end{tabular}




\begin{tabular}{|l|l|l|}
\hline C2.7 F & ACCCAGGAATCCACTCACTTTT & Genotyping F2 for $2:: D s$ \\
\hline C2.7 R & TGCAATCAATAATAGCGTCCAG & Genotyping F2 for $2:: D s$ \\
\hline A5.12 F & AACGTGTAGACCTTGGGTTGAAT & Genotyping F2 for $1: \because D s$ \\
\hline A5.12 R & AGGCGTATAGCGGCTAAGGA & Genotyping F2 for $1: \because D s$ \\
\hline
\end{tabular}

\section{RESULTS}

\section{The maize genome encodes all four components of the CDK8 module of Mediator}

255 A previous effort to identify Mediator genes from many plant species identified a single 256 maize homolog for all four CDK8 module genes (CDK8, CYCC, MED12 and MED13) 257 (Mathur et al., 2011). In order to conclusively define the number and identity of CDK8 258 module homologs in maize, we performed BLAST searches to identify all maize gene259 models (B73 reference genome v3; www.maizesequence.org) whose putative protein 260 products exhibit a high degree of similarity to the entire predicted Arabidopsis proteins of the 261 CDK8 module of Mediator: CDK8 (encoded by HEN3) (Wang and Chen, 2004); CYCC1;1 262 or CYCC1;2 (Wang et al., 2004); MED12 (encoded by CCT/CRP) (Gillmor et al., 2010; 263 Imura et al., 2012); and MED13 (encoded by GCT/MAB2) (Gillmor et al., 2010; Ito et al., 264 2011) (Table 2). Using the translated experimentally verified coding sequences for all maize 265 CDK8 module genes (see below), all potential orthologous relationships were further 266 validated by reciprocal searching of the Arabidopsis genome using maize sequences, and by 267 inspection of the next-best-hit in both Arabidopsis-to-maize and maize-to-Arabidopsis 268 searches (data not shown).

\begin{tabular}{|c|c|c|c|c|c|c|c|c|}
\hline Human & $\begin{array}{c}\text { Hs } \\
\text { GenBank } \\
\text { mRNA }\end{array}$ & Arabidopsis & At $\mathrm{Model}^{1}$ & $\begin{array}{c}A t \\
\text { GenBank } \\
\text { mRNA }\end{array}$ & Maize & $Z m$ Model $^{2}$ & $\begin{array}{c}Z m \\
\text { GenBank } \\
\text { Locus }\end{array}$ & $\begin{array}{l}Z m \text { GenBank } \\
\text { mRNAs }^{4}\end{array}$ \\
\hline CDK8 & P49336 & HEN3 & $\begin{array}{c}\text { AT5G6361 } \\
0.1\end{array}$ & AAT36644 & $Z m C D K 8$ & $\begin{array}{c}\text { GRMZM2G } \\
166771\end{array}$ & $\begin{array}{c}\text { LOC100284 } \\
562\end{array}$ & $\begin{array}{l}\text { EU968864, } \\
\text { NM_00115745 } \\
\text { 7, BT018448; } \\
\text { BT039744, } \\
\text { XR_552425 }\end{array}$ \\
\hline CYCC & P24863 & CYCC $1 ; 1$ & $\begin{array}{c}\text { AT5G4864 } \\
0.1\end{array}$ & BX833973 & $\mathrm{ZmCYCC}$ & $\begin{array}{c}\text { GRMZM2G } \\
408242\end{array}$ & $\begin{array}{l}\text { LOC } 100193 \\
909\end{array}$ & $\begin{array}{l}\text { BT040922, } \\
\text { BT033427, } \\
\text { XM008652706 } \\
\text {; AY105730, } \\
\text { EU972675; } \\
\text { BT036293 }\end{array}$ \\
\hline
\end{tabular}




\begin{tabular}{|c|c|c|c|c|c|c|c|c|}
\hline & & CYCC $1 ; 2$ & $\begin{array}{c}\text { AT5G4863 } \\
0.1 \\
\text { AT5G4863 } \\
0.2\end{array}$ & $\begin{array}{l}\text { AY085977 } \\
\text { BT024473 }\end{array}$ & $\mathrm{N} / \mathrm{A}$ & $\mathrm{N} / \mathrm{A}$ & $\mathrm{N} / \mathrm{A}$ & N/A \\
\hline \multirow[t]{2}{*}{ MED12 } & NP_00511 & $C C T / C R P$ & $\begin{array}{c}\text { AT4G0045 } \\
0.1\end{array}$ & AB690341 & ZmMed12a & $\begin{array}{c}\text { GRMZM2G } \\
114459\end{array}$ & $\begin{array}{c}\text { LOC } 103630 \\
556\end{array}$ & KP455660 \\
\hline & & & & & $\mathrm{ZmMed} 12 \mathrm{~b}$ & $\begin{array}{c}\text { GRMZM5G } \\
828278 / \\
\text { GRMZM5G } \\
844080^{3}\end{array}$ & $\begin{array}{c}\text { LOC } 100384 \\
108\end{array}$ & KP455661 \\
\hline MED13 & NM_0051 & $G C T / M A B 2$ & $\begin{array}{c}\text { AT1G5532 } \\
5.2\end{array}$ & N/A & ZmMed13 & $\begin{array}{c}\text { GRMZM2G } \\
053588 / \\
\text { GRMZM2G } \\
153792^{3}\end{array}$ & $\begin{array}{c}\text { LOC } 100279 \\
/ \\
\text { LOC } 103638 \\
3\end{array}$ & KP455662 \\
\hline
\end{tabular}

${ }^{1}$ TAIR gene models [www.arabidopsis.org] ${ }^{2}$ Maize gene models B73 Reference Genome v3 [maizegdb.org] ${ }^{3}$ Split gene annotation ${ }^{4}$ Independent mRNAs containing full length coding sequences are listed for each splice product. Different spice products are separated by a semi-colon.

270 A single maize gene (GRMZM2G166771) was identified as a potential ortholog of

$271 H E N 3 / C D K 8$, and designated $Z m C D K 8$. Two different full-length splice products were

272 identified for this gene (EU968864 and BT039744), predicted to encode a full-length and a

273 truncated maize CDK8 protein (Figure 1A; Figure S1). The full-length ZmCDK8 protein is

274471 amino acids (AA), and shows 73\% identity with the 470 AA Arabidopsis CDK8 protein,

275 and $43 \%$ identity with the 464 AA human CDK8 protein (Figure S1). The smaller ZmCDK8

276 protein is $385 \mathrm{AA}$, primarily because of a truncation of the $\mathrm{C}$ terminal domain, and shows

$27775 \%$ identity with Arabidopsis CDK8, and 43\% identity with human CDK8. This truncation

278 occurs after the CDK8 kinase catalytic domain (cd07842), and is thus unlikely to interfere

279 with the kinase function of the protein (Figure S1).

280 Although Arabidopsis CYCC is encoded by a tandem-duplicated gene pair (Wang et al., 281 2004), a single potential maize ortholog of CYCC (GRMZM2G408242) was identified, and

282 designated $\mathrm{ZmCycC}$. Figure 1B shows the splice product represented by the full-length cDNA

283 clone BT040922 (Figure 1B). The 257AA BT040922 protein is 42\% identical to human

$284 \mathrm{CycC}$ and $67 \%$ identical to Arabidopsis $\mathrm{CycC} 1 ; 1$ (Figure S2), and contains the Cyclin

285 domain (cd00043) that is present in human and Arabidopsis CycC (Figure S2).

286 BLAST searches using the Arabidopsis CCT/MED12 protein identified two putative full-

287 length maize genes (GRMZM2G114459 on chromosome 1, and the split gene

288 GRMZM5G828278 / GRMZM5G844080 on chromosome 9), which were designated

$289 \mathrm{ZmMed} 12 a$ and $Z m M e d 12 b$. Partial cDNA sequences were publicly available for ZmMED12a

290 and $Z m M e d 12 b$; these sequences, as well as coding sequences predicted by the maize

291 database, were used to experimentally determine mRNA sequences for both genes by RT-

292 PCR. The exon-intron structure of both genes is very similar, with the only differences

293 occurring in the length and position of exons 2, 3 and 4 (Figure 1C\&D). These splicing

294 differences lead to several small insertions or deletions in the N-terminal portions of the

295 ZmMed12 proteins, with ZmMed12a encoding a protein of 2193AA, and ZmMed12b

296 encoding a protein of 2202AA; the two ZmMed12 proteins are 91\% identical (Figure S3).

297 ZmMed12a is 19\% identical to human Med12, and 46\% identical to Arabidopsis MED12; 
ZmMed12b is $20 \%$ identical to human Med12, and 46\% identical to Arabidopsis MED12 (Figure S3). The region of highest identity is that comprising the Med12 domain (pfam09497), located at the N-terminus of the Med12 proteins (Figure S3).

301 A single maize gene was identified corresponding to GCT/MED13 (split gene GRMZM2G053588 / GRMZM2G153792), and designated ZmMed13. Partial cDNA sequences were publicly available for ZmMed13; these sequences were used as the basis for RT-PCR experiments to identify full-length mRNA and coding sequences, which demonstrated that ZmMed13 encodes a protein of 1892 AA, with $20 \%$ identity to human Med13, and 49\% identity to Arabidopsis MED13 (Figure 1E \& Figure S4).

307 Maize CDK8 module genes are expressed throughout development

308 In other organisms where the CDK8 module has been studied, the gene pairs $C D K 8$ and CyclinC; and Med12 and Med13, have similar expression patterns and mutant phenotypes

310 (Yoda et al., 2005; Loncle et al., 2007; Gillmor et al., 2010; Gillmor et al., 2014). In order to determine whether the $C D K 8$ / CycC and Med12 / Med13 genes have similar expression patterns in maize, we used publicly available RNA sequence data to quantify CDK8 module gene expression in different tissues and at different developmental stages (see Materials and Methods). As seen in the heatmap in Figure 2A, $C y c C$ was expressed at much higher levels in all tissues than the other CDK8 module genes, with $C D K 8$ and Med $12 a$ the next highest expressed genes, and Med13 and Med12b with the lowest expression levels

317 In order to more precisely compare tissue-specific expression between the different CDK8 module genes, we made pairwise comparisons for all five genes (Figure 2B \& Figure S5). Expression was most highly correlated for Med13 and Med12b (Pearson's r $=0.93$ ), where the expression ratio between the two genes was close to 1 (compare dotted red line for $\mathrm{r}$, with solid black line representing a 1:1 expression ratio) (Figure 2B \& Figure S5). Med12a and Med12b (r = 0.77); Med12a and Med13 (r=0.7); and CDK8 and Med12a (r =0.76) also had high Pearson's coefficients for pairwise comparisons (Figure 2B \& Figure S5). By contrast, $\mathrm{CycC}$ showed almost no correlation with any of the other CDK8 module genes (Figure 2B \& Figure S5). The fact that $C y c C$ shows little expression correlation with the other CDK8 module genes, and is expressed at higher levels than $C D K 8$, and many times higher than $\mathrm{Med13}, \mathrm{Med} 12 \mathrm{a}$ and $\mathrm{Med} 12 \mathrm{~b}$, suggests that $C y c C$ may play more varied roles in development and physiology than the other CDK8 module genes.

\section{Maize Med12 is encoded by the duplicated gene pair ZmMed12a and ZmMed12b}

330 The high degree of similarity between ZmMed12a and ZmMed12b suggests that they are the result of a recent duplication event (Figure S6). ZmMed12a and ZmMed12b are located in homologous regions of the genome (1S and 9L, respectively), which derive from a polyploidy event that occurred 5-12 million years ago, sometime after the divergence of maize and sorghum lineages. Although gene loss has reduced the number of genes in presentday maize close to pre-duplication levels, in certain cases both syntenic paralogs have been retained (Schnable et al., 2011). Further inspection revealed a sorghum Med12 gene (Sb01g050260; SbMed12) to be present in a region on Chromosome 1L syntenic to the two

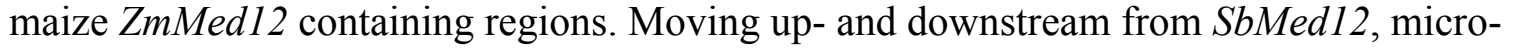

339 synteny was conserved, although, typically, for any given sorghum gene only one candidate 
ortholog was identified in maize, in either the $1 \mathrm{~S}$ or 9L region, presumably as the result of gene-loss within paralog pairs following whole genome duplication (Fig. 3).

\section{Reverse genetics strategies to target maize CDK8 components}

To initiate functional analysis of the maize CDK8 module, we identified publicly available seed stocks carrying $A c / D s$ or $M u$ family transposons inserted into, or close to, maize CDK8 module encoding genes (Table 3). On the basis of this search, we selected ZmMed12a as our first target for reverse genetics: at $\sim 56 \mathrm{~kb}$, the closest potential $D s$ donor was nearer to $\mathrm{ZmMed} 12 a$ than to any of the other genes. In addition, the availability of a well-characterized med 12 mutant in Arabidopsis provides possibility for comparative study (Gillmor et al., 2010; Imura et al., 2012; Gillmor et al., 2014). Finally, the retention of two Med12 syntenic paralogs in maize suggests that the roles of $\mathrm{ZmMed} 12 \mathrm{a}$ and $\mathrm{ZmMed} 12 \mathrm{~b}$ are functionally different, a question which can be addressed by characterization of maize med 12 mutant

\section{3 alleles.}

\begin{tabular}{|c|c|c|c|c|c|}
\hline Maize & Maize Accession & Position (kb) & Closest $A c / D s^{1}$ & Uniform $M u^{2,3}$ & $M u$ Illumina $^{2}$ \\
\hline$Z m C D K 8$ & GRMZM2G166771 & $\begin{array}{l}\text { Chr5: 45,538,294- } \\
45,544,117\end{array}$ & $8311.3 \mathrm{~kb}$ & 3' UTR & 5' UTR \\
\hline $\mathrm{ZmCYCC}$ & GRMZM2G408242 & $\begin{array}{l}\text { Chr7:137,095,918 } \\
137,100,956\end{array}$ & $420 \mathrm{~kb}$ & Upstream & 5' UTR \\
\hline$Z m M E D 12 a$ & GRMZM2G114459 & $\begin{array}{l}\text { Chr1: } 2,088,572- \\
2,102,312\end{array}$ & $56.2 \mathrm{~kb}$ & $\begin{array}{l}\text { Upstream (3), } \\
\text { 5' UTR (4), Int! }\end{array}$ & \\
\hline$Z m M E D 12 b$ & $\begin{array}{l}\text { GRMZM5G828278 } \\
\text { /GRMZM5G844080 }\end{array}$ & $\begin{array}{l}\text { Chr9: } 155,361,528 \\
155,373,747\end{array}$ & $717.1 \mathrm{~kb}$ & 5' UTR (3), Ex' & \\
\hline ZmMED13 & $\begin{array}{l}\text { GRMZM2G053588 } \\
\text { /GRMZM2G153792 }\end{array}$ & $\begin{array}{l}\text { Chr9: } 28,392,287- \\
28,413,513\end{array}$ & $226.7 \mathrm{~kb}$ & & \\
\hline
\end{tabular}

\section{Identification of novel $\mathrm{Ds}$ insertions into $\mathrm{ZmMed12a}$}

To use the $A c / D s$ transposon system to generate mutant alleles of $Z m M e d 12 a$, we first obtained donor $D s(d D s)$ stocks carrying the $D s$ element $d D s-B . S 07.0835$, located $56.2 \mathrm{~kb}$ from $\mathrm{ZmMed12a}$ (acdstagging.org). The position of the linked $D s$ element was confirmed by PCR assay (see Materials and Methods) (Conrad and Brutnell, 2005). Presence of Ac-im in testcross progenitor seed stocks was monitored by somatic excision of a second $D s$ from the $r 1-s c: m 3$ marker locus, resulting in variegated spotting of the kernel aleurone and scutellar tissues (Figure 4A \& B). Spotted kernels were planted and seedlings genotyped for the presence of $d D s$ using a PCR assay (Materials and Methods). To generate novel germinal insertions into $Z m M e d 12 a$, individuals carrying the $d D$ and the $A c$-im transposase source were used as males to pollinate T43 (r-sc:m3/r-sc:m3) females. A test cross population of 59 
ears was obtained for the ZmMed12a screen (Figure 4A\&B).

370 The test-cross population was screened for $D s$ insertions in ZmMed12a using combinations of gene specific and $D s$ specific PCR primers (see Materials and Methods). Pools of 10-18 seedlings were assayed for amplification of putative $D s$-flanking junction products (see Figure 4C for example for the Zmmed12a-2::Ds insertion). Seedlings constituting the pools from which products were amplified were re-screened separately to identify positive individuals (Figure 4D). This second PCR was performed using DNA extracted from a leaf different from that used for the pool PCR to reduce the rate at which we recovered somatic transposition events. We screened a total of 3,049 seedlings and identified two novel insertions into ZmMed12a: zmmed12a-1::Ds, located 918bp upstream of the translational start, and zmmed $12 a-2:: D s$ located in exon 10 (Figure 1C). We performed additional PCR reactions to recover both flanks of the zmmed $12 a-1: \because D s$ and zmmed $12 a-2: \because D$ s insertions. Flanking DNA products were sequenced, confirming the location of the insertions and identifying characteristic $8 \mathrm{bp}$ target site duplications. The seedlings carrying the two novel zmmed $12 a$ insertional alleles were grown to maturity and propagated by both self-pollination and out-crossing. Progeny were germinated and genotyped, confirming the heritability of novel $D s$ insertions (Figure 4E).

\section{The $2:: D s$ insertion results in a truncated $Z m M e d 12 a$ transcript}

In order to determine the effect of these novel $D s$ insertions on the ZmMed12a gene, we performed RT-PCR analysis of plants homozygous for the wild type and Ds alleles, using primer pairs that amplify fragments in exon 9 (downstream of the $1: \because D s$ insertion, and upstream of the $2:: D s$ insertion), and exon 12 (downstream of both $D s$ insertions) (Figure 4F). Both primer sets amplified fragments from wild type and the zmmed12a-1::Ds allele, suggesting that the 1::Ds insertion has no significant effect on the ZmMed12a transcript, a result which is not surprising, since this Ds insertion is upstream of exon 1. In the case of the zmmed $12 a-2: \because D s$ allele, the primer pair in exon 9 produced an amplification product, while the primer pair in exon 12 showed no aplification from homozygous $2: \because D s$ plants. This result demonstrates that the $2: \because D s$ insertion causes production of a truncated version of the $\mathrm{ZmMed12a}$ transcript, likely causing a loss of function of the $\mathrm{ZmMed12a}$ gene.

\section{DISCUSSION}

400 In this study we have identified the five genes encoding the CDK8 module of Mediator in 401 maize, determined their coding sequences, characterized their expression in maize tissues 402 during development, and examined the synteny of maize and sorghum in the region of the $403 \mathrm{Med} 12$ genes. Additionally, we have mutagenized the ZmMed12a gene using the Ac/Ds 404 transposon system created by Vollbrecht et al. (2010).

405 In our analysis of CDK8 module genes, we identified two alternative transcripts for $C D K 8$ (Figure 1). One predicted CDK8 protein is significantly shorter than the other, lacking the Cterminal 86 AA. This truncation seems unlikely to affect enzyme activity per se, as the 
410 CycC, or affect the formation of the four protein CDK8 complex. This complex sterically 411 inhibits the interaction of Core Mediator with RNA pol II, by making direct contact with 412 Core Mediator (Tsai et al., 2013). In the case of $\mathrm{CycC}$, one only one isoform was represented 413 by multiple independent cDNAs. Only single splice products were identified for Med12a, Med12b and Med13 (Figure 1). One explanation for this is that there is indeed only one splice product for each gene in maize. It is also possible that the very large size of the mRNAs for these three genes $(6-7 \mathrm{~kb})$ makes cloning of multiple splice products difficult, due to

418 In our analysis of the relative expression of CDK8 module genes, we found $C D K 8$ and $C y c C$ to be more highly expressed in all tissues than $\mathrm{Med} 12 a, \mathrm{Med} 12 b$ or Med13. In particular, $C y c C$ showed the highest expression in all tissues, consistently 3-4 times higher even than $C D K 8$ (Figure 2). This increased expression of $C y c C$ is consistent with roles of $\mathrm{CycC}$ beyond regulating transcription in tandem with $\mathrm{CDK} 8$ (the best known role for $\mathrm{CycC}$ ) (Allen and Taatjes, 2015). In addition to regulation of transcription, $\mathrm{CycC}$ has been shown to promote the G0 to $\mathrm{G} 1$ cell cycle transition through phosphorylation of Retinoblastoma, allowing quiescent cells to enter the cell cycle. CycC achieves this through interaction with CDK3, a kinase that is not associated with transcriptional activation, but instead promotes cell cycle entry (Ren and Rollins, 2004). CycC has also been demonstrated to be a haploinsuficient tumor suppressor in mammals, whose loss of function in mice is lethal during embryogenesis ( $\mathrm{Li}$ et al., 2014). The haploinsuficiency of CycC may require its mRNA or protein levels to be stably maintained, suggesting an explanation for its high levels in all the tissues that we examined (Figure $2 \&$ Figure S6). Med12a, Med12b, and Med13 show much lower expression levels, which also vary considerably between different tissues (Figure 2 \& Figure S6). The similar expression profiles for Med12 and Med13 in maize are consistent with Arabidopsis, where similar expression profiles for these two genes were reported (Gillmor et al., 2010; Ito et al., 2011; Imura et al., 2012; Gillmor et al., 2014). The widely varying expression levels for Med12 and Med13 in different tissues are consistent with various roles for these genes in development, both in primordia (where they show the highest expression), as well as in differentiating and more mature tissue. In Arabidopsis, MED12 is a single copy gene, with mutant phenotypes in both development and pathogen responses (Gillmor et al., 2010; Imura et al., 2012; Gillmor et al., 2014; Zhu et al., 2014). In maize, however, two Med12 genes were identified. Sometime after divergence with sorghum, the maize lineage underwent whole genome duplication (Schnable et al., 2011). While in the majority of cases resulting additional gene copies have been lost, for $\sim 10 \%$ of the original gene set syntenic paralog pairs have been retained (Hughes et al., 2015). The genomic location of ZmMed12a and ZmMed12b is consistent with them representing such a paralog pair. In the region of synteny between maize and sorghum, other genes surrounding Med12 have been reduced to a single copy, suggesting that the retention of both paralogs of Med12 in maize may have functional significance. Our isolation of the $2: \because D s$ insertional allele of $Z m M e d 12 a$ will allow us to test the functional importance of this gene. The truncation of the ZmMed $12 a$ transcript in the $2:: D s$ allele makes it very likely that this allele causes a loss of function: a T-DNA insertion in a similar location of the CCT (MED12) gene of Arabidopsis causes a strong loss of function phenotype, even when some aberrant transcript is produced (Gillmor et al., 2010; Gillmor et al., 2014) 
454 One additional advantage of $D s$ as a mutagen is that novel transpositions occur into linked

455 sites, meaning that the $D s$ insertions in ZmMed $12 a$ can be remobilized to create further allelic 456 variation in $Z m M e d 12 a$. In addition to mutant alleles that cause a complete loss of function, 457 subsequent $D s$ mutagenesis of $Z m M e d 12 a$ may result in hypomorphic alleles that either 458 reduce (but do not eliminate) the function of $Z m M e d 12 a$, or that inactivate specific functional 459 domains of Med12. Alleles that eliminate only certain parts of the Med12 protein could be 460 especially useful in understanding the function of different domains of Med12, currently one 461 of the most interesting, and least explored, aspects of Mediator biology.

\section{AUTHOR CONTRIBUTIONS}

464 Study designed by TN-R, KA, TPB, SG and RS. Data acquired and/or analyzed by TN-R, 465 KA, ALA-N, DL-S, CM-C, MG-A, SG, RS. Manuscript written by TN-R, SG and RS, and 466 approved by all authors.

\section{CONFLICT OF INTEREST STATEMENT}

468 The authors declare no conflict of interest.

\section{FUNDING}

470 This study was funded by CINVESTAV institutional funds to CSG and RJHS, CONACyT

471 CB 2009 No. 133990 to MGA, CONACyT CB 2012 No. 151947 to RS, and NSF IOS-

4720922701 to TPB. CONACyT graduate fellowships supported TN-R, ALA-N (No. 339468),

473 DL-S (No. 262808), and CM-C (No. 20729).

\section{ACKNOWLEDGEMENTS}

475 Thanks to Cei Abreu-Goodger for advice on analysis of gene expression data, and to Jessica 476 Carcaño-Macías for managing seed stocks.

\section{SUPPLEMENTAL MATERIAL}

478 Supplemental Figures S1-S6.

\section{REFERENCES}

480 Alleman, M., and Kermicle, J. L. (1993). Somatic variegation and germinal mutability reflect 481 the position of transposable element Dissociation within the maize R gene. Genetics 135, 482 189-203.

483 Allen, B.L. and Taatjes, D.J. (2015). The Mediator complex: a central integrator of 484 transcription. Nat Rev Mol Cell Biol 16, 155-166. doi:10.1038/nrm3951

485 Bäckström, S., Elfving, N., Nilsson, R., Wingsle, G., \& Björklund, S. (2007). Purification of 486 a plant mediator from Arabidopsis thaliana identifies PFT1 as the Med25 subunit. Molecular 487 Cell 26, 717-729. http://doi.org/10.1016/j.molcel.2007.05.007 
488 Bai, L., Singh, M., Pitt, L., Sweeney, M., and Brutnell, T. P. (2007). Generating novel allelic 489 variation through Activator insertional mutagenesis in maize. Genetics 175, 981-992.

490 doi:10.1534/genetics.106.066837.

491 Björklund, S., and Gustafsson, C.M. (2005). The yeast Mediator complex and its regulation.

492 Trends Biochem Sci 30, 240-244. doi:10.1016/j.tibs.2005.03.008

493 Bolduc, N., Yilmaz, A., Mejia-Guerra, M. K., Morohashi, K., O'Connor, D., Grotewold, E., 494 et al. (2012). Unraveling the KNOTTED1 regulatory network in maize meristems. Genes Dev 495 26, 1685-1690. doi:10.1101/gad.193433.112.

496 Bolstad, B. M., Irizarry R. A., Astrand, M., and Speed, T. P. (2003). A comparison of 497 normalization methods for high density oligonucleotide array data based on bias and 498 variance. Bioinformatics 19, 185-193.

499

500 Bourbon, H.-M. (2008). Comparative genomics supports a deep evolutionary origin for the 501 large, four-module transcriptional mediator complex. Nucleic Acids Research 36, 3993-4008.

502 doi:10.1093/nar/gkn349

503 Brutnell, T. P., and Dellaporta, S. L. (1994). Somatic inactivation and reactivation of Ac 504 associated with changes in cytosine methylation and transposase expression. Genetics 138, $505213-225$.

506 Brutnell, T.P. and Conrad L.J. (2003). Transposon tagging using Activator (Ac) in maize.

507 Methods Mol Biol 236, 157-176. doi:10.1385/1-59259-413-1:157.

508 Calvi, B. R., Hong, T. J., Findley, S. D., and Gelbart, W. M. (1991). Evidence for a common 509 evolutionary origin of inverted repeat transposons in Drosophila and plants: hobo, Activator, 510 and Tam3. Cell 66, 465-471.

511 Candela, H., and Hake, S. (2008). The art and design of genetic screens: maize. Nat Rev

512 Genet 9, 192-203. doi:10.1038/nrg2291.

513 Conrad, L. J., and Brutnell, T. P. (2005). Ac-immobilized, a stable source of Activator 514 transposase that mediates sporophytic and gametophytic excision of Dissociation elements in 515 maize. Genetics 171, 1999-2012. doi:10.1534/genetics.105.046623.

516 Davidson, R. M., Hansey, C. N., Gowda, M., Childs, K. L., Lin, H., Vaillancourt, B., et al. 517 (2011). Utility of RNA Sequencing for Analysis of Maize Reproductive Transcriptomes. The 518 Plant Genome Journal 4, 191-13. doi:10.3835/plantgenome2011.05.0015.

519 Davis, M. A., Larimore, E. A., Fissel, B. M., Swanger, J., Taatjes, D. J., \& Clurman, B. E. 520 (2013). The SCF-Fbw7 ubiquitin ligase degrades MED13 and MED13L and regulates CDK8 521 module association with Mediator. Genes \& Development 27, 151-156.

522 doi:10.1101/gad.207720.112 
523 Dooner, H. K., and Kermicle, J. L. (1971). Structure of the R tandem duplication in maize.

524 Genetics 67, 427-436.

525 Dooner, H.K. and Belachew, A. (1989). Transposition Pattern of the Maize Element Ac from 526 the Bz-M2(ac) Allele. 122, 447-457.

527 Elmlund, H., Baraznenok, V., Lindahl, M., Samuelsen, C.O., Koeck, P.J.B., Holmberg, S., 528 Hebert, H., and Gustafsson, C.M. (2006). The cyclin-dependent kinase 8 module sterically 529 blocks Mediator interactions with RNA polymerase II. Proc Natl Acad Sci USA 103, 15788530 15793. doi:10.1073/pnas.0607483103

531 Flanagan, P. M., Kelleher, R. J., Sayre, M. H., Tschochner, H., \& Kornberg, R. D. (1991). A 532 mediator required for activation of RNA polymerase II transcription in vitro. Nature 350, 533 436-438. http://doi.org/10.1038/350436a0

534 Furutani, M., Vernoux, T., Traas, J., Kato, T., Tasaka, M., \& Aida, M. (2004). PIN535 FORMED1 and PINOID regulate boundary formation and cotyledon development in 536 Arabidopsis embryogenesis. Development 131, 5021-5030. doi:10.1242/dev.01388

537 Gillmor, C.S., Park, M.-Y., Smith, M.R., Pepitone, R., Kerstetter, R.A., and Poethig, R.S.

538 (2010). The MED12-MED13 module of Mediator regulates the timing of embryo patterning 539 in Arabidopsis. Development 137, 113-122. doi:10.1242/dev.043174

540 Gillmor, C.S., Silva-Ortega, C.O., Willmann, M.R., Buendía-Monreal, M., and Poethig, R.S. 541 (2014). The Arabidopsis Mediator CDK8 module genes CCT (MED12) and GCT (MED13) 542 are global regulators of developmental phase transitions. Development 141, 4580-4589. doi:

$54310.1242 / \mathrm{dev} .111229$

544 Greenblatt, I. M. (1984). A chromosome replication pattern deduced from pericarp

545 phenotypes resulting from movements of the transposable element, modulator, in maize.

546 Genetics 108, 471-485.

547 Imura, Y., Kobayashi, Y., Yamamoto, S., Furutani, M., Tasaka, M., Abe, M., and Araki, T. 548 (2012). CRYPTIC PRECOCIOUS/MED12 is a novel flowering regulator with multiple target 549 steps in Arabidopsis. Plant Cell Physiol. 53, 287-303. doi:10.1093/pcp/pcs002

550 Ito, J., Sono, T., Tasaka, M., and Furutani, M. (2011). MACCHI-BOU 2 is required for early 551 embryo patterning and cotyledon organogenesis in Arabidopsis. Plant Cell Physiol. 52, 539552 552. doi:10.1093/pcp/pcr013

553 Ito, J., Fukaki, H., Onoda, M., Li, L., Li, C., Tasaka, M., Furutani, M., (2016). Auxin554 dependent compositional change in Mediator in ARF7- and ARF19-mediated transcription. 555 Proceedings of the National Academy of Sciences. doi:10.1073/pnas.1600739113

556 Kelleher, R. J., Flanagan, P. M., \& Kornberg, R. D. (1990). A novel mediator between

557 activator proteins and the RNA polymerase II transcription apparatus. Cell, 61, 1209-1215. 
558 Knuesel, M. T., Meyer, K. D., Bernecky, C., \& Taatjes, D. J. (2009). The human CDK8

559 subcomplex is a molecular switch that controls Mediator coactivator function. Genes \&

560 Development, 23, 439-451. http://doi.org/10.1101/gad.1767009

561 Kunze, R., H. Saedler, and W.-E. Lonnig. (1997). Plant Transposable Elements. in Advances

562 in Botanical Research, Academic Press ISBN 978-0-12-005927-0, vol 27, pp350-387.

563 Larivière, L., Seizl, M., and Cramer, P. (2012). A structural perspective on Mediator function.

564 Curr Opin Cell Biol, 24, 305-313. doi:10.1016/j.ceb.2012.01.007

565 Li P., Ponnala L., Gandotra N., Wang L., Si Y., Tausta S. L., Kebrom T. H., Provart N., Patel

566 R., Myers C. R., Reidel E. J., Turgeon R., Liu P., Sun Q., Nelson T. \& Brutnell T. P. (2010).

567 The developmental dynamics of the maize leaf transcriptome. Nature Genetics 42, 1060-

568 1067. doi:10.1038/ng.703.

569 Li, N., Fassl, A., Chick, J., Inuzuka, H., Li, X., Mansour, M. R., et al. (2014). Cyclin C is a

570 haploinsufficient tumour suppressor. Nat Cell Biol 16, 1080-1091. doi:10.1038/ncb3046.

571 Loncle, N., Boube, M., Joulia, L., Boschiero, C., Werner, M., Cribbs, D. L., \& Bourbon, H.-

572 M. (2007). Distinct roles for Mediator Cdk8 module subunits in Drosophila development.

573 EMBO Journal 26, 1045-1054. doi:10.1038/sj.emboj.7601566

574 Mathur, S., Vyas, S., Kapoor, S., and Tyagi, A.K. (2011). The Mediator complex in plants:

575 structure, phylogeny, and expression profiling of representative genes in a dicot

576 (Arabidopsis) and a monocot (rice) during reproduction and abiotic stress. Plant Physiol. 157,

577 1609-1627. doi:10.1104/pp.111.18830

578 McCarty D. R., and Meeley R. B., (2009). Transposon resources for forward and reverse

579 genetics in maize, in Handbook of Maize: Genetics and Genomics, ed. Bennetzen J. L., Hake

580 S., editors. Springer, New York. pp. 561-584

581 Ng, S., Giraud, E., Duncan, O., Law, S. R., Wang, Y., Xu, L., et al. (2013). Cyclin-dependent

582 kinase E1 (CDKE1) provides a cellular switch in plants between growth and stress responses.

583 Journal of Biological Chemistry 288, 3449-3459. doi:10.1074/jbc.M112.416727

584 Plaschka, C., Larivière, L., Wenzeck, L., Seizl, M., Hemann, M., Tegunov, D., et al. (2015).

585 Architecture of the RNA polymerase II-Mediator core initiation complex. Nature 518, 376-

586 380. doi:10.1038/nature 14229

587 R Core Team (2015). R: A language and environment for statistical computing. R Foundation 588 for Statistical Computing, Vienna, Austria. URL https://www.R-project.org/.

589 Ren, S., and Rollins, B. J. (2004). Cyclin C/cdk3 promotes Rb-dependent G0 exit. Cell 117, 590 239-251.

591 Robinson, P. J., Trnka, M. J., Pellarin, R., Greenberg, C. H., Bushnell, D. A., Davis, R., et al. 592 (2015). Molecular architecture of the yeast Mediator complex. Elife 4.

593 doi:10.7554/eLife.08719.

594 Sambrook, J., and Russell, D. W. (2006). Purification of PCR products in preparation for 
595 cloning. CSH Protoc 2006, pdb.prot3825. doi:10.1101/pdb.prot3825.

596 Schnable, J. C., Springer, N. M., and Freeling, M. (2011). Differentiation of the maize 597 subgenomes by genome dominance and both ancient and ongoing gene loss. Proceedings of 598 the National Academy of Sciences 108, 4069-4074. doi:10.1073/pnas.1101368108.

599 Tsai, K.-L., Sato, S., Tomomori-Sato, C., Conaway, R. C., Conaway, J. W., \& Asturias, F. J. 600 (2013). A conserved Mediator-CDK8 kinase module association regulates Mediator-RNA 601 polymerase II interaction. Nature Structural \& Molecular Biology 20, 611-619. 602 http://doi.org/10.1038/nsmb.2549

603 Tsai, K.-L., Tomomori-Sato, C., Sato, S., Conaway, R. C., Conaway, J. W., and Asturias, F. J. 604 (2014). Subunit architecture and functional modular rearrangements of the transcriptional 605 mediator complex. Cell 157, 1430-1444. doi:10.1016/j.cell.2014.05.015.

606 Vollbrecht, E., Duvick, J., Schares, J. P., Ahern, K. R., Deewatthanawong, P., Xu, L., et al. 607 (2010). Genome-wide distribution of transposed Dissociation elements in maize. Plant Cell 608 22, 1667-1685. doi:10.1105/tpc.109.073452.

609 Wang, W. and Chen, X. (2004). HUA ENHANCER3 reveals a role for a cyclin-dependent 610 protein kinase in the specification of floral organ identity in Arabidopsis. Development 131, 611 3147-3156. doi:10.1242/dev.01187

612 Wang, X., Elling, A. A., Li, X., Li, N., Peng, Z., He, G., et al. (2009). Genome-wide and 613 organ-specific landscapes of epigenetic modifications and their relationships to mRNA and 614 small RNA transcriptomes in maize. Plant Cell 21, 1053-1069. doi:10.1105/tpc.109.065714.

615 Wang, G., Kong, H., Sun, Y., Zhang, X., Zhang, W., Altman, N., DePamphilis, C.W., and 616 Ma, H. (2004). Genome-wide analysis of the cyclin family in Arabidopsis and comparative 617 phylogenetic analysis of plant cyclin-like proteins. Plant Physiol. 135, 1084-1099. doi: 618 10.1104/pp.104.040436

619 Warnes, G.R., Bolker, B., Bonebakker, L., Gentleman, R., Huber, W., Liaw, A., Lumley, T., 620 Maechler, M., Magnusson, A., Moeller, S., Schwartz, M., and Venables, B. (2013). gplots:

621 Various $\mathrm{R}$ programming tools for plotting data. $\mathrm{R}$ package version 2.12.1 available at 622 http://CRAN.R-project.org/package=gplots

623 Waters, A. J., Makarevitch, I., Eichten, S. R., Swanson-Wagner, R. A., Yeh, C.-T., Xu, W., et 624 al. (2011). Parent-of-origin effects on gene expression and DNA methylation in the maize 625 endosperm. THE PLANT CELL ONLINE 23, 4221-4233. doi:10.1105/tpc.111.092668.

626 Weigel, D., and Glazebrook, J. (2009). Quick miniprep for plant DNA isolation. Cold Spring 627 Harb Protoc 2009, pdb.prot5179-pdb.prot5179. doi:10.1101/pdb.prot5179.

628 Wu, G., Park, M. Y., Conway, S. R., Wang, J.-W., Weigel, D., \& Poethig, R. S. (2009). The 629 sequential action of miR156 and miR172 regulates developmental timing in Arabidopsis. Cell 630 138, 750-759. doi:10.1016/j.cell.2009.06.031

631 Yin, J.-W. and Wang, G. (2014). The Mediator complex: a master coordinator of 632 transcription and cell lineage development. Development 141, 977-987. 
634 Yoda, A., Kouike, H., Okano, H., Sawa, H., (2005). Components of the transcriptional 635 Mediator complex are required for asymmetric cell division in C. elegans. Development 132, 636 1885-1893. doi:10.1242/dev.01776

637 Zhu, Y., Schluttenhoffer, C. M., Wang, P., Fu, F., Thimmapuram, J., Zhu, J.-K., et al. (2014). 638 CYCLIN-DEPENDENT KINASE8 differentially regulates plant immunity to fungal pathogens through kinase-dependent and -independent functions in Arabidopsis. Plant Cell

640 26, 4149-4170. doi:10.1105/tpc.114.128611

643 Figure 1. The CDK8 module of maize consists of CDK8, CyclinC, Med12a, Med12b, and Med13 (A) Exon-intron structure for two different splice products (EU968864 and BT039744) of the ZmCDK8 gene (GRMZM2G166771). EU968864 encodes a 471AA protein, while BT039744 encodes a 385AA protein, truncated after the CDK8 kinase catalytic domain (cd07842) (B) Exon-intron structure of mRNA sequence BT040922 for the ZmCycC gene (GRMZM2G408242), encoding a predicted protein of 257AA. (C) ZmMed12a (GRMZM2G114459) encodes a 2193 AA protein (mRNA sequence KP455660). The location of the Ds insertions Zmmed 12a-1::Ds (918bp upstream of ATG) and Zmmed12a$2: \because D s$ (exon 10 , at bp 4,236 of coding sequence) are indicated. The orientation of each $D s$ insertion is represented by the triangle above the gene (5'-3'), and below (3'-5'). (D) ZmMed12b (split gene GRMZM5G828278 / GRMZM5G844080) encodes a 2202 AA predicted protein (mRNA sequence KP455661). (E) ZmMed13 (split gene GRMZM2G053588 / GRMZM2G153792) encodes a 1892 AA protein (mRNA sequence KP455662). Intron 11 of ZmMed13 is of unknown size (dotted lines), as it spans a gap in the maize genome sequence. Intron sizes for all genes were determined using corresonding maize genomic sequence. Exons are represented by black boxes, untranslated regions by open boxes, introns by solid black lines, and genomic sequence of ZmMed12a upstream of start codon as

661 Figure 2. CDK8 module genes are broadly expressed in development. (A) Expression of solid grey line. Kilobase of exon per Million reads mapped). Data are from the following sources: Mature tassel, Developing ear, Ovule, Seed 5 dap, Seed 10 dap, Embryo 25 dap, Endosperm 25 dap, Silk, Developing tassel, Ear, Seedling leaves field, Seedling leaves gc (growth chamber) from Davidson et al. (2011). Developing leaf and Mature leaf from Li et al. (2010). Seedling roots and Seedling shoots from Wang et al. (2009). Embryo 14 dap and Endosperm 14 dap from Waters et al. (2011). Shoot apex, Ear primordia, Tassel primordia and Leaf primordia from Bolduc et al. (2012). (B) Correlation of expression patterns for pairwise combinations of members of CDK8 module. Positive correlations are shown as blue circles, with larger circles and darker blue signifying greater correlations between the two genes. Gene-by-gene comparisons for all tissue samples are shown in Figure S5, from which $r$ values to make this plot were taken. 
674 Figure 3. Synteny between maize and sorghum genomic regions surrounding Med12.

675 The Med12 gene is conserved across sorghum and maize syntenic regions. Upper and lower

676 rows: annotated genes in syntenic regions on maize chromosome $1 \mathrm{~S}(\mathrm{Zm} 1 \mathrm{~S})$ at $\sim 2 \mathrm{Mb}$ (upper

677 row), and maize chromosome 9L ( $\mathrm{Zm} 9 \mathrm{~L}$ ) at $\sim 155 \mathrm{Mb}$ (lower row). Middle row: annotated

678 genes in the region of $S b M e d 12$ at $\sim 73 \mathrm{Mb}$ on sorghum chromosome 1L (Sb1L). Orthologous

679 genes are connected by dashed lines. $S b 1 \mathrm{~L}$ and $\mathrm{Zm} 9 \mathrm{~L}$ run left to right, $\mathrm{Zm} 1 \mathrm{~S}$ runs right to left.

680 Genes are shown as black boxes, and the chromosomes are represented by vertical lines.

681 Regions shown to scale, with the right hand position corresponding to the chromosome

682 location mentioned.

683 Figure 4. Generation of $\mathrm{Ds}$ insertional alleles of $\mathrm{ZmMed12a}$, and their effect on the

$684 Z \mathbf{Z m M e d 1 2 a}$ transcript. (A) Crossing scheme for generating plants homozygous for the $r$ -

$685 s c: m 3$ reporter allele, and heterozygous for Ac-immobilized (Ac-im) and the Ds insertion

686 linked to ZmMed12a. (B) The presence of $r$-sc:m3 allows for selection of spotted F1

687 kernels, indicating the presence of $A c$-im, required for remobilizing the $D s$ insertion

688 linked to ZmMed12a. (C) Initial pools of 10-18 seedlings were screened by PCR for the

689 presence of a $D s$ element in ZmMed12a, using gene specific primer E10.2 and Ds specific

690 primer JGp3. A $1.8 \mathrm{~kb}$ fragment (yellow arrow) was amplified from pool C2. (D)

691 Individual plants from pool C2 were tested for the presence of the same fragment, which

692 was amplified from plant 7, denominated C2.7 (Zmmed12a-2::Ds) (E) This 1.8kb band

693 segregated in nine progeny of the selfed plant C2.7, demonstrating that it is a heritable

694 germinal insertion. (F) RT-PCR analysis of the effect of the $1: \because D s$ and $2: \because D s$ insertions

695 on the ZmMed12a transcript. The $1:: D$ s insertion has no detectable effect on the stability

696 of the ZmMed12a transcript, while the $2: \because D s$ insertion creates a transcript that is truncated

697 after the $D s$ insertion. The location of the primer pairs used to amplify the transcript are

698 indicated in the gene diagram. $Z m C D K$ (GRMZM2G149286) was used as a control gene.

699 One representative experiment of three biological replicates is shown. 


\section{A $\quad Z m C D K 8$}

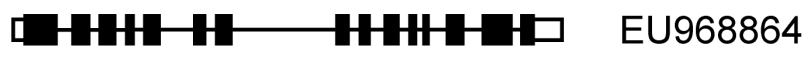

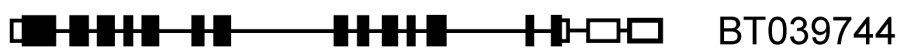

B $\quad \mathrm{ZmCycC}$

口:

C ZmMed12a

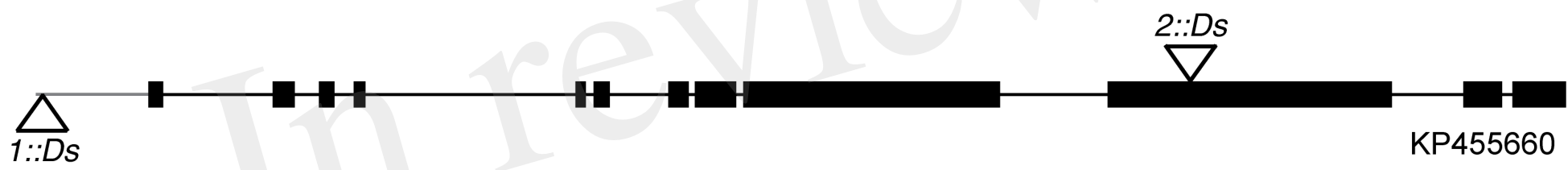

D ZmMed12b

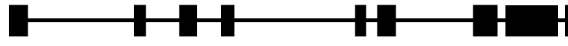

KP455661

$E$

$$
\text { ZmMed13 }
$$

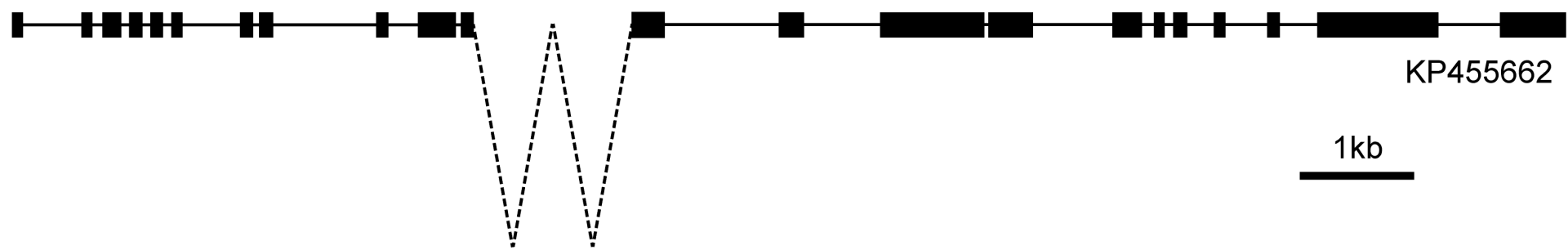

Figure 1 
bioRxiv preprint doi: https://doi.org/10.1101/097204; this version posted December 28, 2016. The copyright holder for this preprint (which was not certified by peer review) is the author/funder. All rights reserved. No reuse allowed without permission.

A Tassel primordia Developing Tassel

Mature Tassel Silk

Ear primordia Developing ear

$$
\text { Ear }
$$

Ovule

Seed 5 dap

Seed 10 dap

Embryo 14 dap

Embryo 25 dap Endosperm 14 dap Endosperm 25 dap

Seedling roots

Seedling shoots

Shoot apex

Seedling leaves field Seedling leaves gc

Leaf primordia

Developing leaf Mature leaf

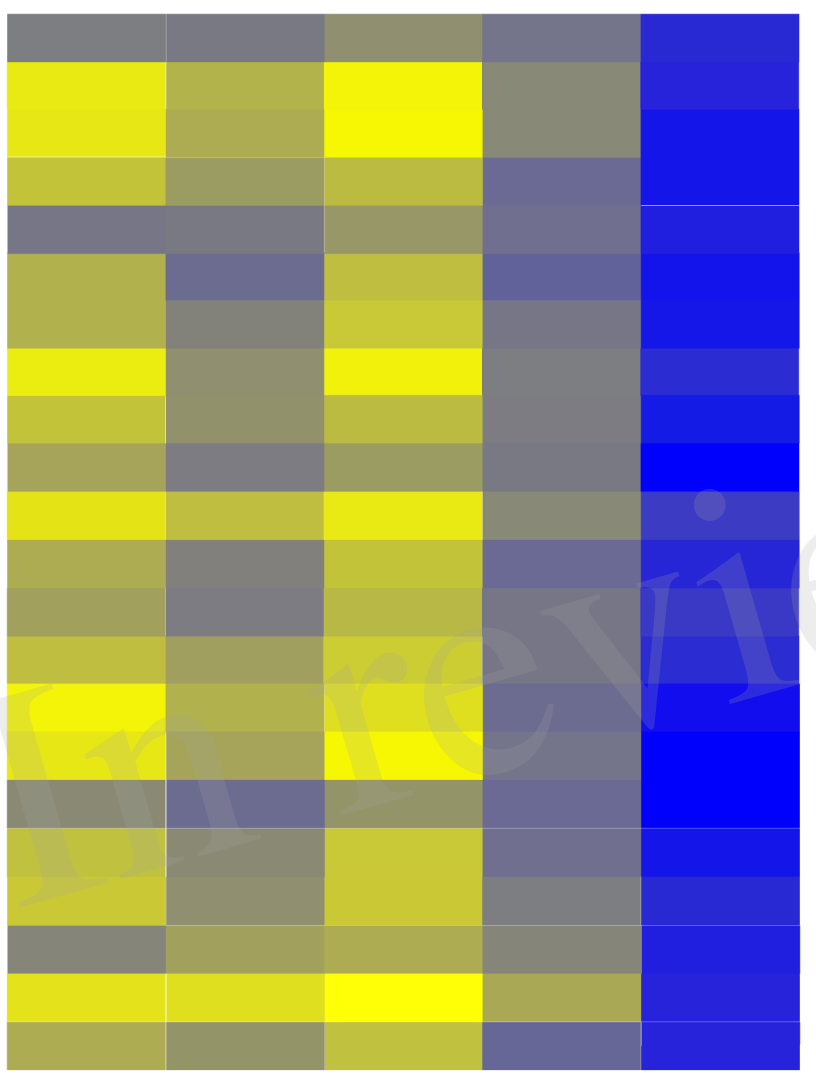

B

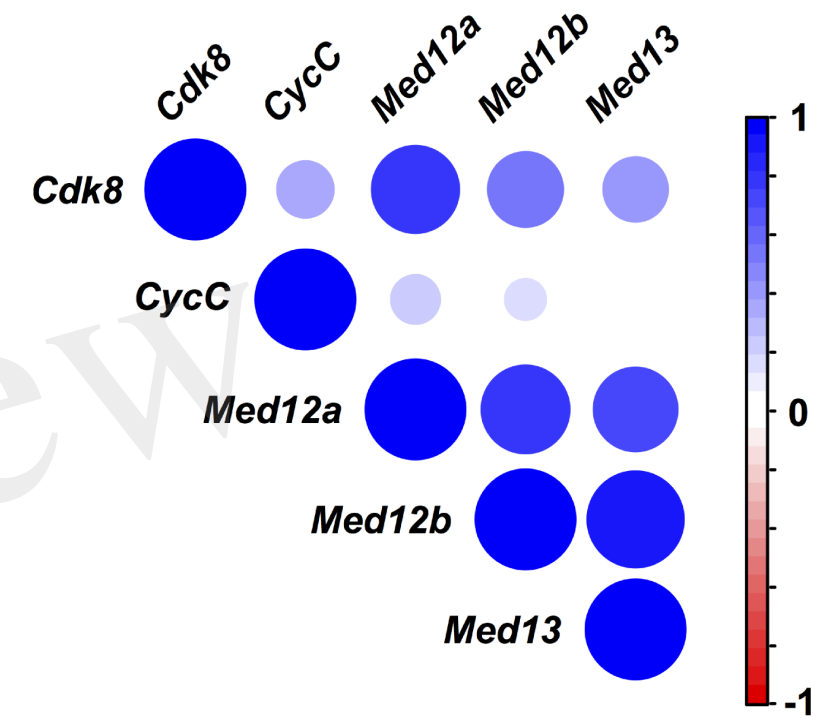

Med13 Med12a Med12b CDK8 CycC

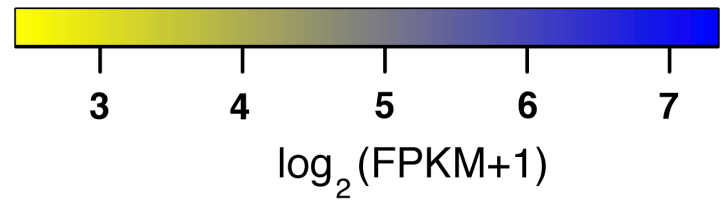

Figure 2 
bioRxiv preprint doi: https://doi.org/10.1101/097204; this version posted December 28, 2016. The copyright holder for this preprint (which was not certified by peer review) is the author/funder. All rights reserved. No reuse allowed without permission.

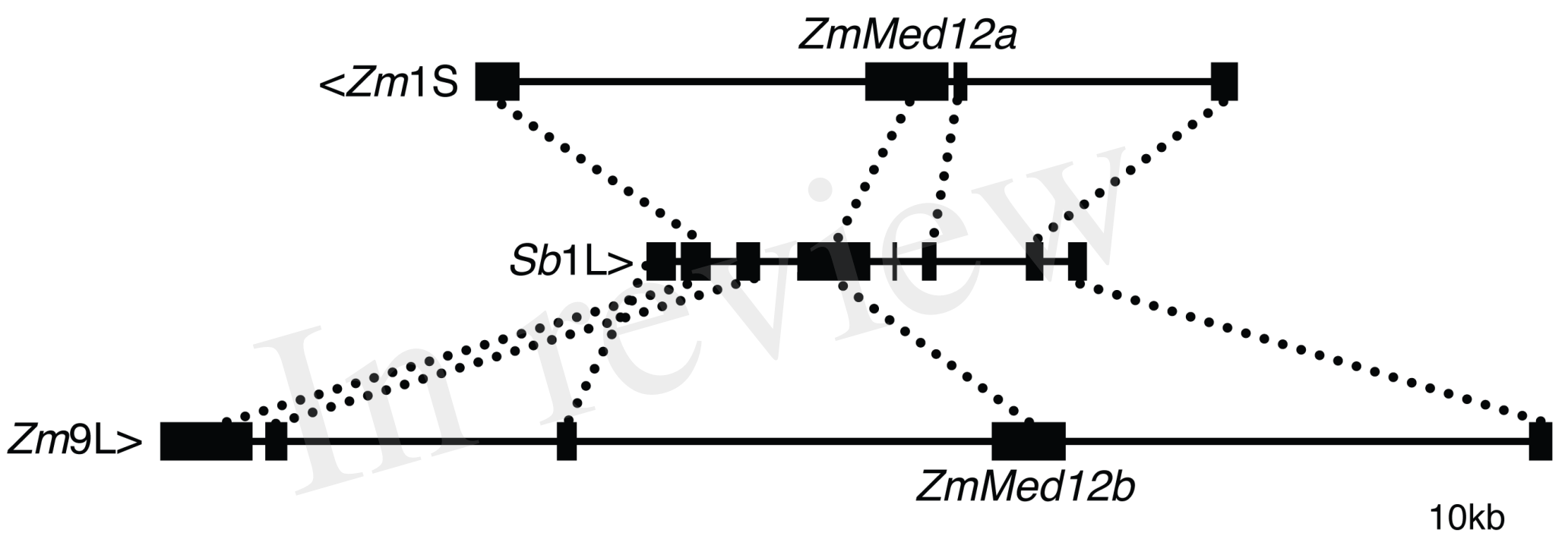

Figure 3 

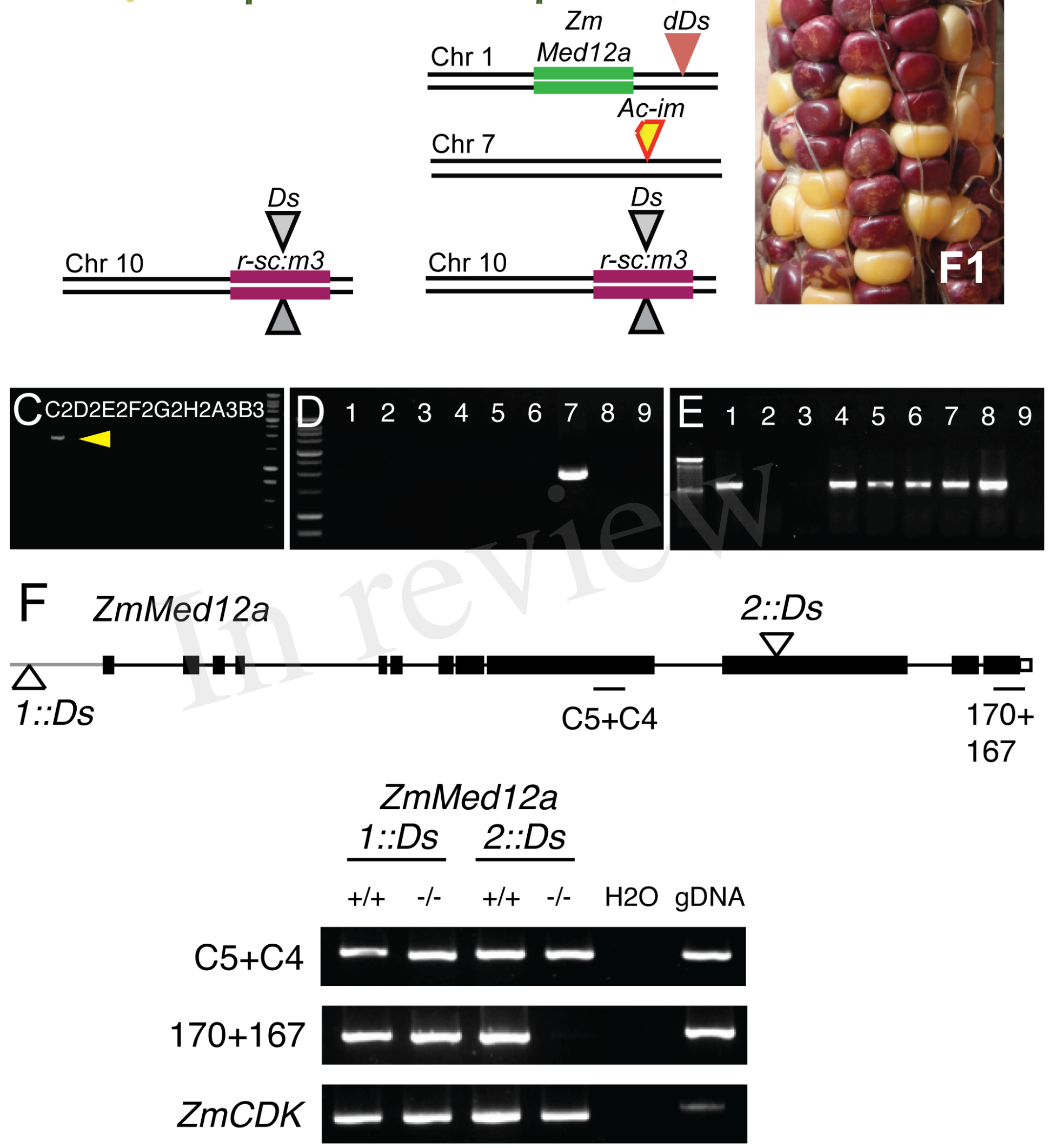